\title{
Chronic mucocutaneous candidiasis
}

\author{
NiEls RosmaN \\ M.D. \\ Skin Clinic, Hillered, Denmark
}

\begin{abstract}
Summary
The pathogenesis of chronic mucocutaneous candidiasis is surveyed. Treatment comprises topical antifungal treatment which is insufficient, systemic antifungal treatment which is often followed by a rapid relapse, and specific immunotherapy with live tissue or transfer factor. Combination of systemic antifungal therapy and immunotherapy seems to be the most promising approach. However, no permanent cure has so far been achieved.
\end{abstract}

MAN lives in a delicate balance with Candida albicans which is an integral part of human microbial flora. Many minor changes in the internal and external environment may tip the scales in favour of the fungus so that from a harmless saprophyte it becomes a true pathogen. One of the most remarkable and rare causes of superficial candidiasis is an inherent deficiency in the immune defence. The defect which is responsible for the candidiasis resides in the T lymphocytes (Valdimarsson et al., 1970). The function of the B lymphocytes may also be impaired, supposedly owing to some $T$ cell influence on the B cell function, as other components of the $B$ cell function such as production of specific precipitins are sometimes even more pronounced than normally (Cahill, Ainbender and Glade, 1974). Combined immune deficiencies such as lymphopenic agammaglobulinaemia also have candidiasis as part of the syndrome. In most cases of chronic mucocutaneous candidiasis the mechanism is still so obscure that it is difficult to characterize, even with the present most sophisticated methods.

The disease usually starts in early childhood with a persistent oral thrush and a papular rash in the napkin area, but it may also arise in early adolescence. The skin lesions gradually progress into widespread erythematous scaling plaques, particularly on the extremities. The plaques may augment to boggy hyperkeratotic lesions called Candida granulomas. Skin infection is later followed by nail infection, producing thickened and brownish dis-

Correspondence: Slotsgade 14, DK 3400 Hillerød, Denmark. coloured nails. The patients have chronic thrush on genital skin, and mucous membranes in the mouth and oesophagus, but systemic candidiasis is never seen.

Although the fungal infection is the most conspicuous feature of the syndrome other symptoms are more decisive for the outcome. The patients have recurrent bacterial infections in the upper respiratory tract and sometimes detrimental virus infections such as herpes simplex, herpes zoster, and hepatitis. Later in the course of the disease they often develop endocrinopathies, e.g. hypoparathyroidism, hypothyroidism and hypoadrenalism. The severest cases are those with stem cell defect, thymus aplasia or hypoplasia. These usually have a fatal outcome in early life. What are mostly referred to as cases of chronic mucocutaneous candidiasis are those with the above mentioned symptoms with a prolonged, non-fatal course. One group has a particularly benign course and a candidiasis restricted to mucous membranes and nails. It is in this latter group that genetic factors are especially important (Higgs and Wells, 1972; Rothschild et al., 1976; Okamoto et al., 1977).

The last ten years' impressive development in the knowledge of immune mechanisms has meant giant steps forward in understanding the background of chronic mucocutaneous candidiasis and has offered possibilities of a causal treatment. So the treatment may be of the traditional type directed towards the invading pathogens, or the newly recognized one centred round the host.

The modern antifungal drugs for candidiasis are flucytosine; imidazole derivatives, e.g. clotrimazole, miconazole and econazole; polyenes, e.g. amphotericin B, nystatin and natamycin. All these drugs can be used topically and some of them systemically.

The imidazole derivatives constitute a new and expanding group of drugs which are effective in treatment of all common fungal skin infections. Topical treatment can occasionally show a dramatic and fairly long-lasting result in chronic mucocutaneous candidiasis (Figs 1,2). The effect will eventually fade and topical treatment can never entirely 


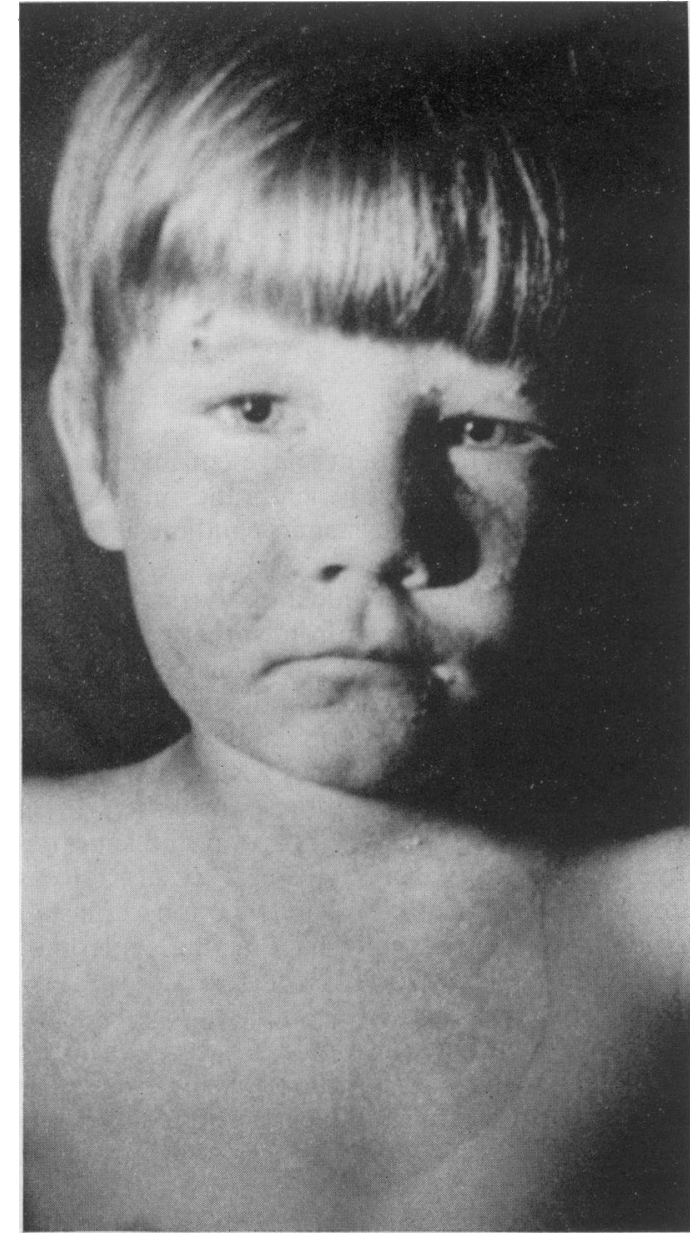

Fig. 1. Before topical treatment with clotrimazole.

clear a patient. At most it can reduce symptoms and probably also reduce the antigen load on the organism and as such is still justified. Topical use of amphotericin B and flucytosine in this disease should be restricted to supplementing the systemic use of the same drugs.

The most effective drug for systemic treatment is amphotericin B. It is administered i.v. 3 days each week until complete clearance is achieved, which may be in 8 to 10 weeks. Towards the end of the treatment period, infected nails are avulsed under general anaesthesia. By this treatment, relapse-free periods of up to 3 years may be achieved, as may the reversal of a negative Candida skin test to a positive one (Kirkpatrick and Smith, 1974). By combining it with flucytosine, the dose of amphotericin B can be

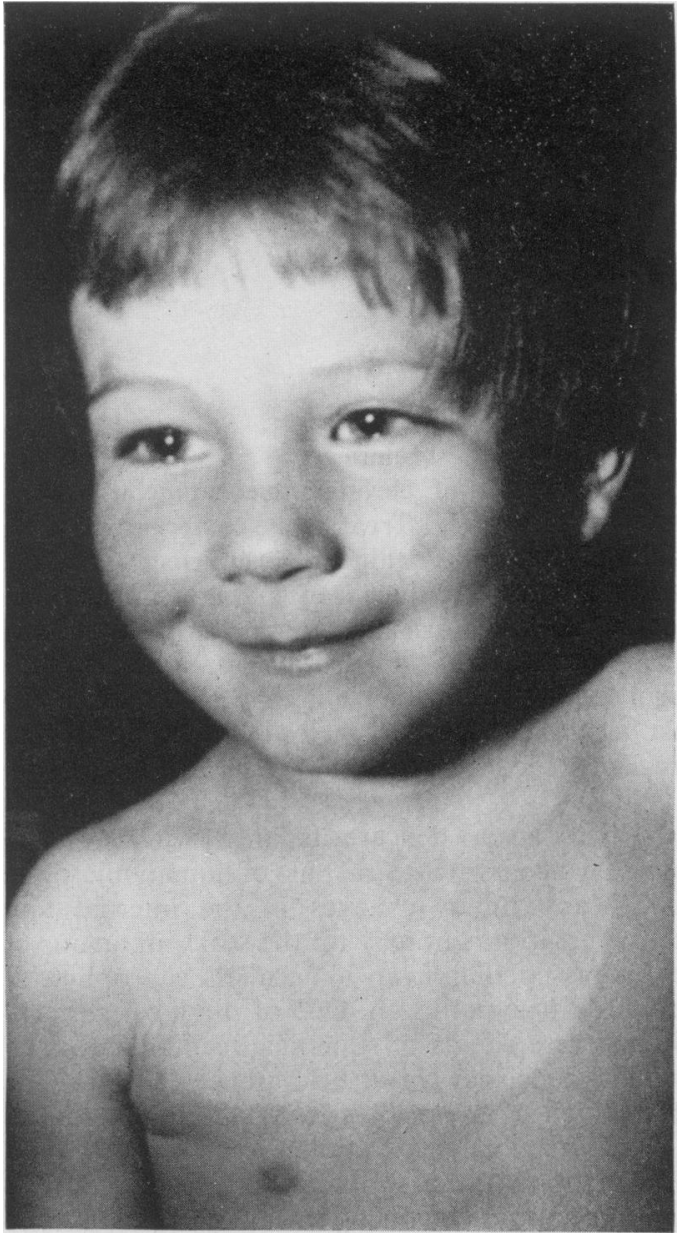

Fig. 2. After 2 months' topical treatment with clotrimazole.

reduced and thereby the inescapable side effects. Such excellent results are however exceptional. Usually the skin lesions will relapse a few weeks after stopping the treatment (Kirkpatrick, Rich and Bennett, 1971).

Combined oral and local treatment with flucytosine alone continued for some months has also resulted in recovery. After 3 months the dose had to be increased from $100 \mathrm{mg}$ to $150 \mathrm{mg} / \mathrm{kg} / \mathrm{day}$. The only side effect seemed to be a persistent elevation of transaminases and alkaline phosphatase (Touraine et al., 1972).

The imidazole derivatives clotrimazole and miconazole are commercially available only for topical use, and for systemic use only on special request. Clotrimazole is absorbed well from the intestine, so it is 
administered orally in a daily dosage of $60 \mathrm{mg} / \mathrm{kg}$. This dose will usually have to be increased after a few weeks' treatment because of liver enzyme induction and an increase in the rate of drug metabolism. By intermittent administration long-term treatment has given good clinical results, reduced the clinical resistance and thus kept the side effects at a minimum (Ipp, Boxall and Gelfand, 1977; Meade, 1977; Quadripur, 1975).

Miconazole is poorly absorbed when taken orally. Nevertheless, it has proved effective by oral administration in a 12-year-old child who was given $750 \mathrm{mg}$ thrice daily, reduced to $250 \mathrm{mg} /$ thrice daily when satisfactory clinical response was gained (Lorente et al., 1977). By intravenous administration the daily dose of miconazole is $30-60 \mathrm{mg} / \mathrm{kg}$. Marked improvement was reported from 5 children, although not without adverse reactions (Fischer et al., 1977). To avoid relapses, miconazole may also be given as a long-term, intermittent therapy.

Thus an antifungal treatment is not a waste of time and effort, but the results - especially judged by the duration of relapse-free periods - are unpredictable. So it was with great expectation that the prospect of a possible reconstitution of the host's immune defence was received when it was first mooted some 10 years ago.

Before discussing specific immunotherapy there is a non-specific treatment to be mentioned. Iron deficiency is a constant finding in chronic mucocutaneous candidiasis-even in patients with a normal haemoglobin (Higgs and Wells, 1972). Sideropenic anaemia is often present in the most severely affected patients.

Restoration of normal iron levels has proved effective not only on the clinical manifestations of candidiasis, but normalization of immune responses has also been partly achieved (Higgs, 1973). Favourable results were, however, restricted to the group of mild cases affecting only mouth and nails. In the group of diffuse cutaneous candidiasis the iron treatment failed.

Specific reconstitution of cellular immunity is attempted in different ways. The severest deficiencies such as lymphopenic agammaglobulinaemia, aplasia or hypoplasia of thymus (DiGeorge, and NezelofAllibone syndromes) have been treated by transplantation of bone marrow, fetal haemopoietic tissue, fetal thymus tissue and lymphocytes. Complete chimerism may result but there is an impending risk of a fatal graft-versus-host reaction, especially when bone marrow and lymphocytes are used. This risk is not so high in the treatment of patients with non-fatal chronic mucocutaneous candidiasis who have defects on a higher level in the maturation of the lymphocytes. Bone marrow transplantation has been successful (Buckley et al., 1968). Less favour- able results have come from the use of lymphocytes with good HLA-compatibility (Kirkpatrick et al., 1971).

Because transplantation of live allogeneic tissue to an immune-deficient host will always imply a certain risk, not only of a fatal outcome but also of an immune disease (Ballow and Hyman, 1977) it is no surprise that interest has mainly focused on the use of transfer factor. This is an extract of lymphocytes, whose exact chemical nature and way of operating is still obscure. It is essential in this context that the transfer factor derives from persons with a strong allergy to Candida (Kirkpatrick, Rich and Smith, 1972). Amount and dosage schedules vary from study to study and so do the results. Some are very favourable - chiefly in mild cases (Berthaux et al., 1972; Sousa et al., 1976). In most other studies only slight and transient reversal of the in vivo and in vitro immune tests resulted and no clinical improvement (Kirkpatrick et al., 1971; Kirkpatrick and Smith, 1974). Far more effective is transplantation of fetal thymus tissue which can be given intramuscularly or intraperitoneally (Levy et al., 1971; Ballow and Hyman, 1977).

If systemic treatment with amphotericin B is given before the immune therapy the antigen load on the feeble immune defence is relieved and a more lasting effect results. This is seen when amphotericin B is followed-up by repeated transfer factor injections. More than 2 years' freedom from candidiasis has been obtained (Kirkpatrick and Smith, 1974). In cases where even this procedure has been unsuccessful a combination immunotherapy can be applied (Ballow and Hyman, 1977). Systemic amphotericin B followed by injection of fetal thymus tissue and followed-up by repeated transfer factor treatment has been very successful and the patient was still clear one year later. No chimerism resulted as no new HLA antigens were noted. The existence of a thymus hormone is therefore suggested.

There is no such thing as a standard treatment for chronic mucocutaneous candidiasis. The highly varying results of treatment are due to different treatment schedules but more than anything else to the fact that chronic mucocutaneous candidiasis is not a homogeneous pathogenic entity. The choice of treatment in an individual case is dependent on the correct assessment of the severity of the clinical condition and one must aim to give a treatment which is no more hazardous than this assessment justifies.

\section{References}

Ballow, M. \& Hyman, L.R. (1977) Combination immunotherapy in chronic mucocutaneous candidiasis. Synergism between transfer factor and fetal thymus tissue. Clinical Immunology and Immunopathology, 8, 504. 
Berthaux, P., Moulias, R., Goust, J.-M., Reinert, P. \& FouRNEL, J.J. (1972) Immunothérapie adoptive spécifique par le facteur de transfert de l'immunité à médiation cellulaire. Résultats préliminaires d'un facteur de transfert semi-purifié. Annales de Médecine Interne, 123, 1069.

Buckley, R.H., LuCAS, Z.J., HatTler, B.G., ZMiJewsKi, C.M. \& AmOs, D.B. (1968) Defective cellular immunity associated with chronic mucocutaneous moniliasis and staphylococcal botryomycosis: immunologic reconstitution by allogeneic bone marrow. Clinical and Experimental Immunology, 3, 153.

Cahill, L.T., Ainbender, E. \& Glade, P.R. (1974) Chronic mucocutaneous candidiasis: $T$ cell deficiency associated with B cell dysfunction in man. Cellular Immunology, 14, 215.

Fischer, T.J., Klein, R.B., Kershnar, H.E., Borut, T.C. \& STIEHM, E.R. (1977) Miconazole in the treatment of chronic mucocutaneous candidiasis: a preliminary report. Journal of Pediatrics, 91, 815.

HIGGS, J.M. (1973) Chronic mucocutaneous candidiasis: iron deficiency and the effect of iron therapy. Proceedings of the Royal Society of Medicine, 66, 802.

HiggS, J.M. \& Wells, R.S. (1972) Chronic mucocutaneous candidiasis: associated abnormalities of iron metabolism. British Journal of Dermatology, 86, 88.

IPP, M.M., BoXall, L. \& GelfaND, E.W. (1977) Clotrimazole. Intermittent therapy in chronic mucocutaneous candidiasis. American Journal of Diseases of Children, 131, 305.

KiRKPATRICK, C.H., Rich, R.R. \& BENNETT, J.E. (1971) Chronic mucocutaneous candidiasis: model-building in cellular immunity. Annals of Internal Medicine, 74, 955.

KIRKPATRICK, C.H., Rich, R.R. \& SMITH, T.K. (1972) Effect of transfer factor on lymphocyte function in anergic patients. Journal of Clinical Investigation, 51, 2948.
KiRkPATRICK, C.H. \& SMith, T.K. (1974) Chronic mucocutaneous candidiasis: immunologic and antibiotic therapy. Annals of Internal Medicine, 80, 310.

Levy, R.L., Huang, S.-W., BaCh, M.L., BaCh, F.H., HoNG, R., Ammann, A.J., Bortin, M. \& KAY, H.E.M. (1971) Thymic transplantation in a case of chronic mucocutaneous candidiasis. Lancet, ii, 898.

Lorente, F., Fontan, G., Rodriguez, M.C.G. \& Ojeda, J.A. (1977) Treatment of chronic mucocutaneous candidiasis with imidazole derivatives. Journal of Pediatrics, 90, 847.

MEADE, R.H. (1977) Treatment of chronic mucocutaneous candidiasis. Annals of Internal Medicine, 86, 314.

OKamoto, G.A., Hall, J.G., Ochs, H., Jackson, C., Rodaway, K. \& Chandler, J. (1977) New syndrome of chronic mucocutaneous candidiasis. Birth Defects, 13, 117.

QuADRIPUR, S.A. (1975) Verlauf einer chronischen mucocutanen Candidose unter Clotrimazol- und 5-Fluorocytosin-Behandlung. Mykosen, 18, 299.

Rothschild, H., Wilson, M., Lopez, M., Salvaggio, J. \& BICE, D. (1976) An immunological investigation of a family with chronic mucocutaneous candidiasis. International Archives of Allergy and Applied Immunology, 52, 291.

Sousa, M. De, Cochran, R., Mackie, R., Parratt, D. \& Arala-Chaves, M. (1976) Chronic mucocutaneous candidiasis treated with transfer factor. British Journal of Dermatology, 94, 79.

Touraine, R., Revuz, J., Larrègue, M., Duterque, M., JoufFroy, L., Roujeau, J.-C., WeChSLER, J. \& VION, M. (1972) Candidoses cutanéo-muqueuses chroniques. Annaleso de Médecine interne, 123, 737.

VAldimarsson, H., Holt, L., Riches, H.R.C. \& HobBs, J.R (1970) Lymphocyte abnormality in chronic mucocutaneous candidiasis. Lancet, i, 1259. 